\title{
ROLAND BARTHES, EL TEXTO Y EL PODER
}

Alejandro Querejeta Barceló

"Lo que toda mi vida me ha apasionado es la manera en que los hombres hacen inteligible el mundo. Es, si usted quiere, la aventura de lo inteligible, el problema de la significación".

Roland Barthes ${ }^{l}$

$\mathrm{N}$ o solo la academia, sino también decenas de medios de comunicación conmemoran en 2015 el centenario del nacimiento del filósofo, escritor, crítico, ensayista y semiólogo francés Roland Barthes (1915-1980). En estos días se dice que construyó textos apasionantes, "de dócil lectura", que en vida gozó de "cierto prestigio y tribuna debido a sus polémicas con Jean Paul Sartre, a quien se atrevió a contradecir al afirmar que "el primer compromiso del escritor no es con el mundo o sus problemas, sino con la escritura, la palabra, el lenguaje". Que asumió un papel "desestabilizador" de los saberes de su tiempo y puso en evidencia la fragilidad conceptual de los métodos académicos convencionales. Que, además, arremetió con una lógica implacable contra el ejercicio de la crítica de entonces (y de hoy) al sostener que "aunque por su función hable del lenguaje de los otros, hasta el punto de querer aparentemente (y a veces abusivamente) concluirlo, el crítico, como el escritor, nunca tiene la última palabra"².

En una crónica a raíz de su muerte, el novelista italiano Ítalo Calvino consideró que "toda su obra, ahora lo veo, consiste en forzar la impersonalidad del mecanismo lingüístico y cognitivo para que refleje la fisicidad del sujeto viviente y mortal"'s. En definitiva, Barthes continúa poniéndonos delante el problema de cómo entender el acto de la escritura como irradiador de significancias que nos impregnan, de las que no podemos escapar.

$1 \quad$ Citado por Verónica Chiaravalli, 'Barthes o la aventura de lo inteligible' en Buenos Aires, diario La Nación, 15 de mayo de 2015, en http://www.lanacion.com.ar/1792808-bartheso-la-aventura-de-lo-inteligible

2 Giancarlo Stagnaro, 'Roland Barthes, Ensayos críticos, Buenos Aires: Seix Barral, 2003', en Elhablador.com, No.8, junio de 2005, http://www.elhablador.com/resena8_3.htm,

3 Italo Calvino, 'En memoria de Roland Barthes (1980)', Ignoria, 19 de noviembre de 2011, http://bibliotecaignoria.blogspot.com/2011/11/italo-calvino-en-memoria-de-roland.html 
Un tema que, en el fondo, es el que nos ocupa en la actualidad en los ámbitos público y académico, ante los embates del poder contra ejercicios de escritura como el periodístico. En su ensayo sobre Kafka, por ejemplo, es notable su reflexión sobre que la verdad del escritor judío no es su mundo, sino los signos de ese mundo. En consecuencia, su tarea (la de Kafka) es la de luchar para, en lo posible, saber cuál es el sentido de la vida. Una búsqueda del sentido de la vida que ocupa y preocupa en el ejercicio responsable de la comunicación en cualquier soporte en que se opere.

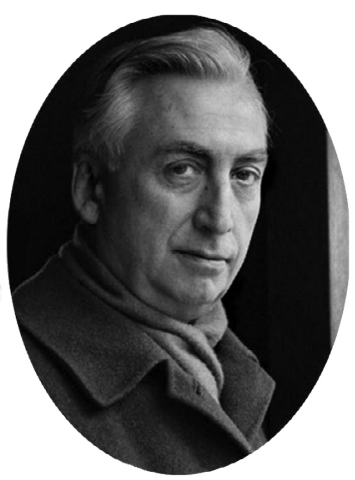

Roland Barthes

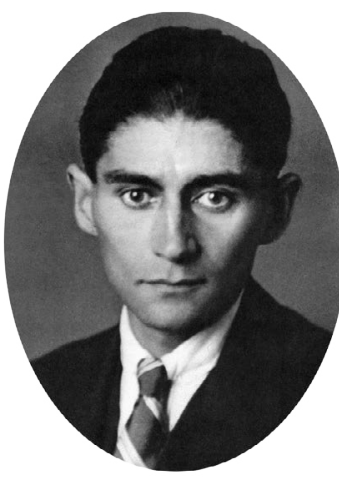

Franz Kafka

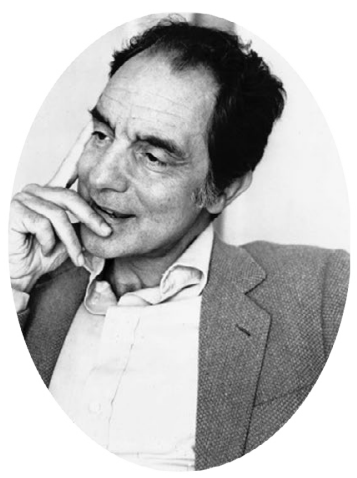

Italo Calvino

\section{Groserías sin significación}

Barthes en el 'Prólogo' de su libro El grado cero de la escritura recordaba el caso de un escritor que comenzaba sus textos con alguna palabrota que, en definitiva, no significaba nada, pero que reflejaba una situación revolucionaria. Y decía: "He aquí el ejemplo de una escritura cuya función ya no es sólo comunicar o expresar, sino imponer un más allá del lenguaje que es a la vez la historia y la posición que se tome frente a ella"4. Por entonces, el paleontólogo y filósofo francés Teilhard de Chardin, refiriéndose al universo, hablaba de un tránsito de lo ínfimo a lo inmenso, de la relación estructural entre complejidad y conciencia, "de lo más simple a lo más extremadamente complicado", afirmaciones que bien podrían aplicarse, a manera de complemento, a las tesis de Barthes respecto a la lengua, el signo, el lenguaje, el texto y la literatura, en la que incluyo, como su manifestación cotidiana, factual, básica e irradiante, al periodismo. Al respecto, vale recordar a Barthes en su Lección Inaugural:

Entiendo por literatura no un cuerpo o una serie de obras, ni siquiera un sector de comercio o enseñanza, sino la grafía compleja de las marcas de una práctica, la práctica de escribir. Veo entonces en ella esencialmente al texto, es decir, al tejido de significantes que constituye la obra, puesto que el

\footnotetext{
$4 \quad$ Roland Barthes, El grado cero de la escritura, Puede consultarse en varios sitios electrónicos. Utilizamos http://www.cholonautas.edu.pe/modulo/upload/Roland\%20Barthes.pdf $5 \quad$ Teilhard de Chardin, El fenómeno humano, Madrid, Taurus, 1967, p. 364.
} 
texto es el afloramiento mismo de la lengua, y que es dentro de la lengua donde la lengua debe ser combatida, descarriada: no por el mensaje del cual es instrumento, sino por el juego de las palabras cuyo teatro constituye. Puedo entonces decir indiferentemente: literatura, escritura o texto. Las fuerzas de libertad que se hallan en la literatura no dependen de la persona civil, del compromiso político del escritor, que después de todo no es más que un "señor" entre otros, ni inclusive del contenido doctrinario de su obra, sino del trabajo de desplazamiento que ejerce sobre la lengua ${ }^{6}$.

Como en el caso de la práctica periodística, "la literatura toma a su cargo muchos saberes [...] la literatura hace girar los saberes, ella no fija ni fetichiza ninguno; les otorga un lugar indirecto [...] el saber que ella moviliza jamás es completo ni final"’ Es decir, nos adentramos en un territorio extragenérico o supragenérico, según se mire, en donde el texto como tal todo lo incluye, pues se trata de un "soporte material donde se plasma el contenido de un mensaje", donde cada enunciado comporta un material informativo, bien sea conocido o novedoso ${ }^{8}$. Por otra parte, en El grado cero de la escritura (1953), Barthes considera que la libertad de quien escribe (escritor o periodista, en nuestro caso), no tiene los mismos límites en diferentes momentos de la Historia. El filósofo, ensayista y crítico literario argentino Dardo Scavino, en la revista $\tilde{\mathcal{N}}$, señala que para Barthes:

\section{ROLAND BARTHES}

\section{EL GRADO CERO DE LA ESCRITURA}

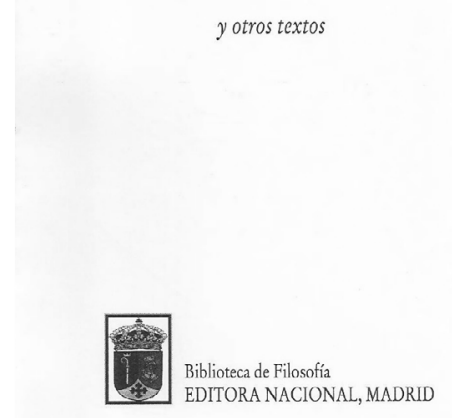

El Grado Cero de la Escritura (1953), fue uno de los primeros ensayos importantes de Barthes

6 Roland Barthes, El placer del texto y Lección Inaugural. Buenos Aires, Siglo XXI Editores. 2003, p.98.

$7 \quad$ Ibídem, p. 99.

$8 \quad$ Véase al respecto el Breve diccionario de términos literarios de Demetrio Estébanez Calderón, Madrid, Alianza Editorial, 2000, p. 508-509. 


\begin{abstract}
Los humanos no se limitan a emitir signos cuando se expresan oralmente o por escrito sino también cuando se mueven, comen, beben, se visten, se casan, practican ciertos rituales, edifican sus viviendas o adhieren a grupos políticos, en fin: cuando actúan socialmente. Una práctica es social, desde la perspectiva de Barthes, cuando nos libra un mensaje: una cruz o un cigarrillo no son solamente signos culturales -señas identificadoras-sino también citas, alusiones intertextuales a sujetos que emplearon esos signos o maneras de inscribirse en una tradición o una moda ${ }^{9}$.
\end{abstract}

Dice Barthes, además, que ninguna escritura es neutra, que aquellas que "parecen ser más despojadas están persiguiendo la búsqueda de un efecto de sentido"10. Añaden algunos estudiosos de su obra, que para el pensador francés "un texto es creado por una multiplicidad de conciencias, culturas, ideas, pensamientos, filosofías e ideologías" Y que "no existen discursos neutros, asépticos, y que toda pretensión de objetividad ('el grado cero') era, por lo tanto, imposible ('no hay lenguaje escrito sin ostentación'). Entonces, en el caso de los políticos, comunicadores por naturaleza y necesidad, su lenguaje nunca es inocente, pues "en cada discurso se evidencia una tradición a la cual pertenece y de la cual el autor no puede escindirse" ${ }^{\prime 1}$.

\title{
Un asunto de estilo
}

Sin embargo, a ciertos escritos, evidentementeporsuestilo,losllamó “textosescribibles", porque "permiten crear e involucrarse", y "muchos de ellos, que, en proporciones semejantes, conmueven, enamoran y hacen pensar" ${ }^{2}$. Para Barthes el estilo es, en definitiva, un "lenguaje autárquico que se hunde en la mitología personal y secreta del autor". Añade en El grado cero de la escritura que "sea cual fuere su refinamiento, el estilo siempre tiene algo en bruto: es una forma sin objetivo, el producto de un empuje, no de una intención, es como la dimensión vertical y solitaria del pensamiento. Sus referencias se hallan en el nivel de una biología o de un pasado, no de una Historia: es la "cosa" del escritor, su esplendor y su prisión, su soledad. Indiferente y transparente a la sociedad, caminar cerrado de la persona, no es de

$9 \quad$ Dardo Scavino, El planeta de los signos, en Revista $\tilde{\mathcal{N}}, 5$ de junio de 2015, www. clarin.com/rn/ideas/filosofia/planeta-signos_0_1370862919.html

10 Julian Gorodischer, ‘¿Existe el grado cero de la escritura?', en Revista $\tilde{\mathcal{N}}, 10$ de septiembre de 2013, http://www.revistaenie.clarin.com/ideas/Existe-grado-cero-escritura_0_988701138.html.

$11 \quad$ Laura Ventura, 'El semiólogo más sensual: 7 claves para entender a Roland Barthes', en Diario La Nación, 7 de agosto de 2015, http://www.lanacion.com.ar/1816847-el-semiologomas-sensual-7-claves-para-entender-a-roland-barthes

12 Desde el punto de vista de quien consume el texto, "existe un lector comprometido, con un interés directo y personal por la noticia y una aguda comprensión de la misma. Hay también un lector interesado; no desempeña un pale directo en el tema que se está tratando pero la información le afecta y, en virtud de alguna experiencia personal, conocerla puede provocar cierta reacción de su parte. Y hay, por último, un lector no interesado, que presta poca atención a la noticia y la leerá, si es que llega a hacerlo, una vez que otros hayan esbozado previamente una orientación sobre la misma", Bill Kovach y Tom Rosenstiel, Los elementos del periodismo, Madrid, Prisa Ediciones, 2012, p. 39. 
ningún modo el producto de una elección, de una reflexión sobre la Literatura. Es la parte privada del ritual, se eleva a partir de las profundidades míticas del escritor y se despliega fuera de su responsabilidad"13.

Varias veces se citó este fragmento de su libro póstumo El susurro del lenguaje (1984):

\begin{abstract}
El problema del estilo solo puede tratarse en relación a lo que yo llamaría el hojaldre del discurso; y, para seguir con las metáforas alimenticias, resumiré estas opiniones diciendo que, si bien hasta el presente se ha visto el texto con la apariencia de un fruto con hueso (un albaricoque, por ejemplo) cuya pulpa sería la forma y la almendra sería el fondo, hoy conviene verlo más bien con la apariencia de una cebolla, organización a base de pieles (niveles, sistemas), cuyo volumen no conlleva finalmente ningún corazón, ningún hueso, ningún secreto, ningún principio irreductible, sino la misma infinitud de sus envolturas, que no envuelven otra cosa que el mismo conjunto de sus superficies ${ }^{14}$.
\end{abstract}

Esta analogía a la que echó mano muchos años después Günter Grass en su memorioso y revelador libro Pelando la cebolla (2007), permite avanzar en la lectura de un texto, basados en su deconstrucción ${ }^{15}$. De esta manera, esta "metáfora alimenticia", nos pone delante un método para el abordaje de un texto cualquiera., que nos permite ir develando, en la medida que penetramos en el texto, "la infinitud de sus envolturas", encontrar sus muy variadas fuentes de significado. Con ella nos transformamos en un lector activo, desveladores del ajuste expresivo del texto, del sistema que lo estructura y anima, la aprehensión de sus esencias, que no excluye aquella "vía simpática" tan apreciada y exaltada por Julio Cortázar, uno de nuestros autores latinoamericanos más fecundos y originales, que permite "penetrar en su verdadera dimensión" ${ }^{\prime 16}$.

13 Roland Barthes, El grado cero de la escritura. Madrid, 1973. Siglo XXI.

14 Roland Barthes, El susurro del lenguaje, Barcelona, Paidós, 2009. Ver comentario de Verónica Nieto, ¿Hojaldre, rizoma, trenza cosida (un homenaje a Roland Barthes)' en Rumiar la biblioteca, http://rumiarlabiblioteca.blogspot.com/2015/07/hojaldre-rizoma-trenza-cosidaun.html\#sthash.pHVnG8fP.dpuf

15 Günter Grass, Pelando la cebolla, Madrid, 2008, 517 p. En este libro autobiográfico, Grass aborda momentos de su propia vida, capa tras capa, a la manera de la "metáfora alimenticia” de Barthes. El "inventor" del término deconstrucción, Jacques Derrida en ‘Qué es la deconstrucción?', dice: “Si yo quisiera dar una descripción económica, elíptica, de la deconstrucción, diría que es un pensamiento del origen y de los límites de la pregunta ‘qqué es...?', la pregunta que domina toda la historia de la filosofía. Cada vez que se intenta pensar la posibilidad del '¿qué es...?', plantear una pregunta sobre esta forma de pregunta, o de interrogarse sobre la necesidad de este lenguaje en una cierta lengua, una cierta tradición, etc., lo que se hace en ese momento sólo se presta hasta un cierto punto a la cuestión “¿qué es?"”. Ver la revista Artillería Inmanente, http://artilleriainmanente.blogspot.com/2013/11/jacques-derrida-que-es-la-deconstruccion.html

16 Julio Cortázar, La vuelta al día en ochenta mundos, t. II, México, Siglo XXI, 2008, pp. 41-81. 


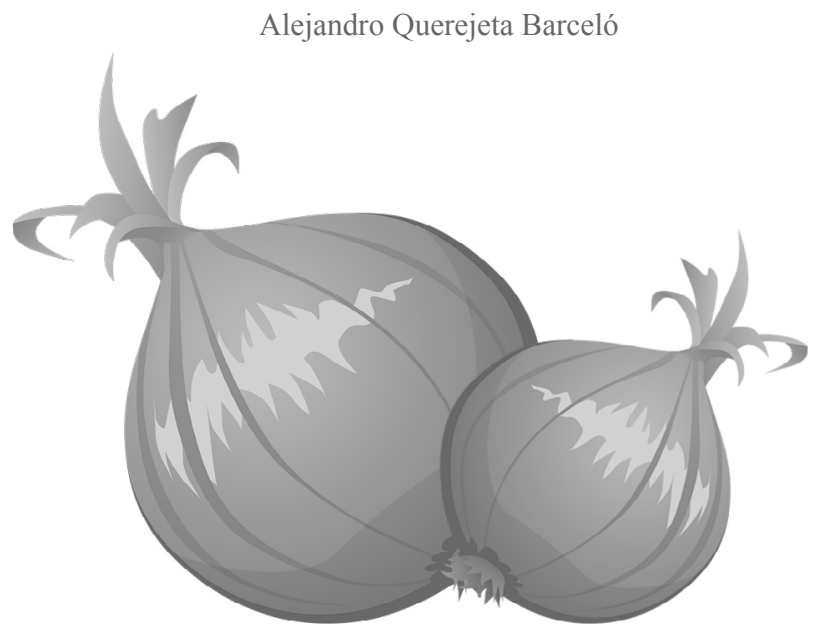

Para Grass, un texto cualquiera, al igual que una cebolla, se lo puede analizar 'por capas'.

A partir de la realidad de que "todo el mundo está instalado en la tranquila certidumbre de un universo sin duplicidad" ${ }^{17}$, en sucesivos abordajes del problema del texto, Barthes destaca su pluralidad de significados, sus límites formales, que lo vuelven abierto a una gran multiplicidad de interpretaciones. Al referirse a la obra de Julio Verne, por ejemplo, señala que "construyó una suerte de cosmogonía cerrada sobre sí misma, que posee sus propias categorías, su tiempo, su espacio, su plenitud e inclusive su principio existencial":

Este principio creo que se encuentra en el gesto continuo del encerramiento. La imaginación del viaje corresponde en Verne a una exploración de lo cerrado; la coincidencia de Verne con la infancia no proviene de una mística banal por la aventura, sino de una felicidad común por lo finito, que puede encontrarse en la pasión infantil por las cabañas y las tiendas de campaña: el sueño existencial de la infancia y de Verne consiste en amurallarse e instalarse. El arquetipo de este sueño es esa novela casi perfecta, La isla misteriosa, donde el hombre-niño reinventa el mundo, lo llena, lo cerca, se encierra dentro de él y corona este esfuerzo enciclopédico con la postura burguesa de la apropiación: pantuflas, pipas y un rincón del hogar, mientras afuera la tormenta, es decir el infinito, se enfurece inútilmente.

\section{Texto y poder}

"El texto es (o al menos debería ser) esa persona audaz que muestra su trasero al Padre Político", escribió Barthes en su libro titulado El placer del texto $(1973)^{18}$. En nuestros

17 Ver: 'Falsas evidencias de imágenes cotidianas' en Revista $\tilde{\mathcal{N}}, 12$ de junio de 2015, diario Clarín, donde se dice: "Mitologías. Aquí, algunos fragmentos de los textos -escritos entre 1954 y 1956, y reunidos en formato libro en 1957- en los que Barthes realiza, tempranamente, una lectura crítica del lenguaje de la llamada cultura de masas; como bien subrayó 'al calor de la actualidad"”. http://www.revistaenie.clarin.com/ideas/Roland-Barthes-Mitologias_0_1370862924.html

$18 \quad$ Roland Barthes, El placer del texto y Lección inaugural, Buenos Aires, Siglo XXI, 2008, p.70. 
días, en América Latina, quien hiciera esto tendría que soportar una avalancha de rectificaciones y aclaraciones desde el poder, independientemente de sufrir represalias legales. En El grado cero de la escritura indicó, sin embargo, "no hay duda de que cada régimen posee su escritura, cuya historia está todavía por hacerse. La escritura, siendo la forma espectacularmente comprometida de la palabra, contiene a la vez, por una preciosa ambigüedad, el ser y el parecer del poder, lo que es y lo que quisiera que se crea de él: una historia de las escrituras políticas constituiría por lo tanto la mejor de las fenomenologías sociales".

Pero hay más, en su Lección inaugural de la cátedra de Semiología Literaria del Collège de France, pronunciada el 7 de enero de 1977, advertía:

\footnotetext{
La "inocencia" moderna habla del poder como si fuera uno: de un lado los que lo poseen, del otro los que no lo tienen; habíamos creído que el poder era el poder era un objeto ejemplarmente político, y ahora creemos que es también un objeto ideológico, que se infiltra hasta allí donde no se lo percibe a primera vista - en las instituciones, en las enseñanzas-, pero que en suma es siempre uno. Pero ¿y si el poder fuera plural, como los demonios? "Mi nombre es Legión", podría decir: por doquier y en todos los rincones, jefes, aparatos, masivos o minúsculos, grupos de opresión o de presión; por doquier voces "autorizadas", que se autorizan para hacer escuchar el discurso de todo poder: el discurso de la arrogancia ${ }^{19}$.
}

En un viejo diccionario de sinónimos, que heredé de mi padre, se dice que "el poder está en relación con la fuerza", que "el poder lleva", que "un caballo tiene poder", que "el poder nos viene de la naturaleza". Que el término procede "del latín possum, potes, compuesto de pos y sum: soy potente". Y lo asocia con potestad, y señala que "la potestad está en relación con el dominio", que "la potestad manda", que "un monarca tiene potestad" y que la potestad se asocia con la política ${ }^{20}$.

Según Barthes, "no hay duda de que cada régimen posee su escritura, cuya historia está todavía por hacerse. La escritura, siendo la forma espectacularmente comprometida de la palabra, contiene a la vez, por una preciosa ambigüedad, el ser y el parecer del poder, lo que es y lo que quisiera que se crea de él: una historia de las escrituras políticas constituiría por lo tanto la mejor de las fenomenologías sociales"21. Y sentencia: "Este hecho de escritura es por otra parte propio de todos los regímenes autoritarios; es lo que se podría llamar la escritura policial: se conoce, por ejemplo, el contenido eternamente represivo de la palabra 'orden'”.

\footnotetext{
$19 \quad$ Ibídem, p. 94.

20 Roque Barcia, Sinónimos castellanos, Buenos Aires, Editorial Sopena, 1958, p. 378.

21 Roland Barthes, El grado...
} 
En su Diccionario de la Política, Norberto Bobbio advierte que "todo poder trata de ganarse elconsenso para que sele reconozca comolegítimo, transformandola obediencia en adhesión”22, lo que podríamos combinar con las ideas de poder y potestad de Roque Barcia citadas al principio de este párrafo. A lo que vale añadir esta reflexión de Roland Barthes en la Lección inaugural:

\begin{abstract}
Adivinamos entonces que el poder está presente en los más finos mecanismos del intercambio social: no sólo en el Estado, las clases, los grupos, sino también en las modas, las opiniones corrientes, los espectáculos, los juegos, los deportes, las informaciones, las relaciones familiares y privadas, y hasta en los accesos liberadores que tratan de impugnarlo: llamo discurso de poder a todo discurso que engendra la falta, y por ende la culpabilidad del que lo recibe. Algunos esperan de nosotros, intelectuales, que actuemos en toda ocasión contra el Poder; pero nuestra verdadera guerra está en otra parte; está contra los poderes, no se trata de un combate fácil porque, plural en el espacio social, el poder es, simétricamente, perpetuo en el tiempo histórico: expulsado, extenuado aquí, reaparece allá; jamás perece: hecha una revolución para destruirlo, prontamente va a revivir y a rebrotar en el nuevo estado de cosas. La razón de esta resistencia y de esta ubicuidad es que el poder es el parásito de un organismo transocial, ligado a la entera historia del hombre, y no solamente a su historia política, histórica. Aquel objeto en el que se inscribe el poder desde toda la eternidad humana es el lenguaje o, para ser más precisos, su expresión obligada: la lengua ${ }^{23}$.
\end{abstract}

\title{
Textualidad e hipertexto
}

Barthes, en su abordaje al problema de texto, llama la atención, además, sobre el hecho de que el texto único "no es acceso (inductivo) a un modelo, sino entrada a una red con mil entradas; seguir esta entrada es vislumbrar a lo lejos no una estructura legal de normas y desvíos, una Ley narrativa o poética, sino una perspectiva (de fragmentos, de voces venidas de otros textos, de otros códigos), cuyo punto de fuga es, sin embargo, incesantemente diferido, misteriosamente abierto: cada texto (único) es la teoría misma (y no el simple ejemplo) de esta fuga, de esta diferencia que vuelve indefinidamente sin conformarse" "24. Para Barthes esa pluralidad de significados del texto es "una fiesta" en donde "las palabras ya no son concebidas ilusoriamente como simples instrumentos, sino lanzadas como proyecciones, explosiones, vibraciones, maquinarias, sabores; la escritura convierte al saber en una fiesta" ${ }^{25}$.

Recientemente, elfilósofo y ensayista españolJosé Luis Pardo consideraba que la palabra mágica en muchas de las reflexiones de Barthes es “texto”. Decía: “Texto, una práctica de la escritura que ya no es literatura 'en el sentido burgués de la palabra', que desactiva las rígidas fronteras entre los géneros literarios y que permite, por ejemplo, defender la

22 Norberto Bobbio, Diccionario de la política, en http://www.ps-santafe.org/admin/upload/d2/ApuntesdelDiccionariodePoltica.pdf

23 Roland Barthes, El placer del texto y Lección inaugural, pp. 94-95.

24 Roland Barthes, S/Z, Madrid. Siglo XXI, 1980, pp., 8-12.

$25 \quad$ Roland Barthes, El placer del texto..., p. 100. 
identidad estructural entre el trabajo 'filológico' de Vladimir Propp sobre la morfología del relato y el trabajo 'pictóric"' de Mondrian sobre la geometría de las formas visuales, o entre la etnopsiquiatría de Georges Dumezil y la música de Pierre Boulez”26.

Dice Barthes que en el texto, en consecuencia, "abundan las redes (réseaux) que actúan entre sí sin que ninguna pueda imponerse a las demás; este texto es una galaxia de significantes y no una estructura de significados; no tiene principio, pero sí diversas vías de acceso, sin que ninguna de ellas pueda calificarse de principal; los códigos que moviliza se extienden hasta donde alcance la vista; son indeterminables". Un ideal de textualidad el de Barthes que, se dice, "coincide exactamente con lo que se conoce como hipertexto electrónico, un texto compuesto de bloques de palabras (o de imágenes) electrónicamente unidos en múltiples trayectos, cadenas o recorridos en una textualidad abierta, eternamente inacabada y descrita con términos como nexo (enlace), nodo, red, trama y trayecto" ${ }^{27}$.

[...] para Barthes en ese texto ideal abundan las redes, las cuales actúan entre sí sin que ninguna pueda imponerse a las demás. Además, ese texto es "una galería de significantes" y no una estructura de significados. No tiene principio más sí diversas vías de acceso, aun cuando ninguna de ellas pueda catalogarse de principal.// Los códigos de ese texto ideal, según Barthes, se extienden hasta donde alcance la vista y son interminables. Los sistemas de significados pueden imponerse a ese texto plural, pero nunca su número estará limitado, puesto que se fundamenta en la infinidad del lenguaje ${ }^{28}$.

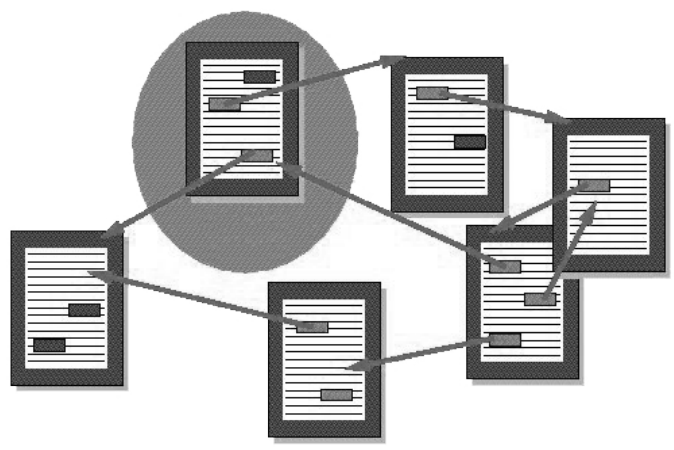

\section{El hipertexto, para Barthes, significan las conexiones creadas entre varios textos y como estos se complementan el uno al otro a través de palabras claves}

26 José Luis Pardo, 'Los años salvajes del lenguaje', Madrid, diario El País, 12 de julio de 2015, http://cultura.elpais.com/cultura/2015/07/09/actualidad/1436442392_552588.html. 27 Joseba Abaitua. Programa de doctorado en Lengua y Literatura, 1996/97 y 1998/99. Bilbao, Facultad de Filosofía y Letras. Universidad de Deusto, País Vasco, http://paginaspersonales. deusto.es/abaitua/konzeptu/htxt/hipertxt.htm. Ver: Roland Barthes. S/Z. París, Éditions du Seuil, 1970.

28 Carlos Abreu Sojo, El periodismo en internet, Caracas, Fondo Editorial de Humanidades y Educación, 2003, p. 68. 
De esta manera, estamos en presencia de un hipertexto, es decir, un texto compuesto de fragmentos de texto o que conecta, por los canales que considere su usuario, con otros muchos, a veces distantes de la lengua y la cultura de quien los procura. A esto le llamó Barthes lexías o unidades que dan cuenta de los significados, para realizar cinco lecturas posibles: psicológica, psicoanalítica, temática, histórica y estructural. Así, entramos en el terreno del "texto electrónico", que implica no solo un soporte tecnológico en particular, sino también una forma específica de edición, con sus propias peculiaridades $^{29}$. Ya en 1965, el filósofo, sociólogo y pionero de la tecnología de la información norteamericano Theodor H. Nelson señalaba que:

\begin{abstract}
“Con 'hipertexto' me refiero a una escritura no secuencial, a un texto que bifurca, que permite que el lector elija y que se lea mejor en una pantalla interactiva. De acuerdo con la noción popular, se trata de una serie de bloques de texto conectados entre sí por nexos, que forman diferentes itinerarios para el usuario [...] Hipertexto es una combinación de textos en lenguaje natural y la capacidad del ordenador de exposición dinámica de un texto no lineal [...] "Hipertexto es el término genérico; hay varios motivos para excluir otros conceptos posibles como 'texto con ramificaciones', 'texto con estructura gráfica', ‘texto complejo' o ‘texto arborescente' [...] La mejor definición de hipertexto, que cubre una gran variedad de tipos, es 'estructura que no se puede imprimir en modo apropiado'. Esta definición no es ni muy específica ni profunda, pero es aquella más apta..."”o.
\end{abstract}

\title{
Barthes y la fotografía
}

Alguien ha recordado en este centenario de su nacimiento, que Barthes a lo largo de su actividad intelectual no dejó de interesarse en la publicidad, revistas de moda, cine y la fotografia, sobre la que escribirá La cámara lúcida $(1980)^{31}$.En este ensayo, sostiene Laura Ventura, "agudizaba su lente para analizar los elementos retóricos, o de connotación, que integran a la fotografia, y a los que equipara con un lenguaje integrado por signos alfabéticos. El semiólogo se propone otra titánica tarea: comprender el motivo

29 "El hipertexto es una estructura que organiza la información de forma no lineal. La estructura hipertextual permite saltar de un punto a otro en un texto -o a otro texto- a través de los enlaces. En lugar de leer el texto de forma continua, ciertos términos están unidos a otros mediante relaciones a través de los enlaces. Esto permite que los lectores o usuarios de un hipertexto accedan a la información que les interese de forma directa o que la busquen de acuerdo con sus propios intereses, sin tener que recorrer el texto entero paso a paso o secuencia a secuencia. Lo que convierte a un texto en hipertexto es la enorme capacidad que le dan los vínculos o enlaces dentro de una estructura de múltiples ramificaciones. Este tipo de estructura y esta forma de organizar la información es sólo posible gracias a la utilización de un medio digital, un hipertexto sólo puede realizarse y tomar forma gracias a los ordenadores”. Ver: María Jesús Lamarca Lapuente. Hipertexto: El nuevo concepto de documento en la cultura de la imagen, http:/ /www. hipertexto.info/documentos/hipertexto.htm

$30 \quad$ Ibídem.

31 Eduardo Berti, "Una revolución llamada Roland Barthes" en, Buenos Aires, ADN Cultura, diario La Nación, 15 de mayo de 2015, http://www.lanacion.com.ar/1792811-una-revolucion-llamada-roland-barthes 
por la cual una imagen genera determinado efecto en su observador. La fotografía, para Barthes, posee un poder fáustico: detiene el tiempo y burla a la muerte"32.

RolandBarthesmuriópocotiempo después de publicado este libro, el 25 demarzo de ese año. Fuevíctima de un accidente de tránsito, en el cruce de la rue des Ecoles y la rue Saint-Jacques Íta, a dos pasos del College de France. Le condujeron al hospital de la Salpetriere, dice Ítalo Calvino que "como un herido sinnombre(nollevabadocumentos encima)". Allí muere más tarde por complicaciones pulmonares.

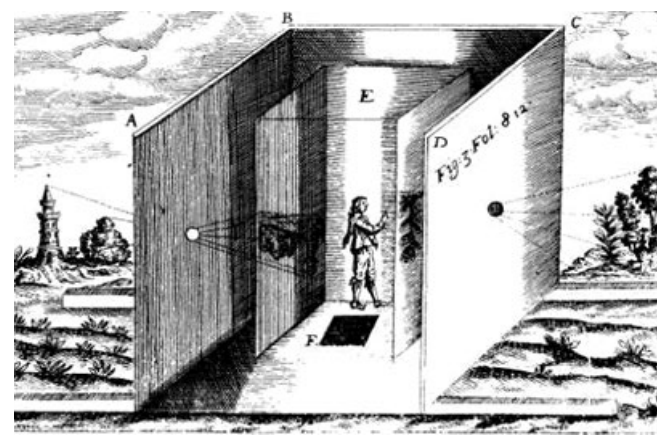

La 'cámara oscura' es un aparato que refleja un elemento tridimensional (A) en una superficie plan e invertida (B)

Calvino, que fue su alumno, como Georges Perec y Julia Kristeva, dice haber leído un poco el libro y que le había "conmovido sobre todo las bellísimas páginas sobre la experiencia de ser fotografiado, sobre la desazón de ver el propio rostro convertido en objeto, sobre la relación entre la imagen y el yo"33. Añade que La cámara lúcida es una "aproximación progresiva a una definición de ese tipo particular de conocimiento que abre la fotografía, 'objeto antropológicamente nuevo"”. Observa Calvino que:

\footnotetext{
Barthes distingue en el interés que una foto suscita en nosotros un nivel que es el del studium o participación cultural en la información o en la emoción que la imagen transmite, y el del punctum, o sea el elemento sorprendente, involuntario, conmovedor, que ciertas imágenes comunican. Ciertas imágenes o mejor ciertos detalles de imágenes: la lectura que Barthes hace de las obras de fotógrafos famosos o anónimos es siempre inesperada: a menudo son pormenores físicos (manos, uñas), o vestimentarios aquellos cuya singularidad pone de relieve.
}

Evidentemente relacionado con La cámara lúcida, 20 años antes Barthes publicó un ensayo relativamente breve titulado "El mensaje fotográfico" (que reproducimos a continuación a manera de complemento de todo lo dicho hasta aquí con fines estrictamente docentes y como homenaje a Barthes en el centenario de su nacimiento), en el que no solo ilumina aspectos fundamentales para la fotografía periodística, sino que, además, establece una metodología para su análisis crítico.

$\begin{array}{ll}32 & \text { Laura Ventura, ob. cit. } \\ 33 & \text { Italo Calvino, ob. cit. }\end{array}$ 


\section{Páginas Salvadas}

\section{ROLAND BARTHES}

\section{"EL MENSAJE FOTOGRÁFICO”}

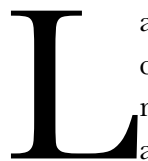

a fotografía periodística es un mensaje. El conjunto de ese mensaje está constituido por una fuente emisora, un canal de transmisión y un medio receptor. La fuente emisora es la redacción del diario, el grupo de técnicos, algunos de los cuales sacan la fotografía, otros la seleccionan, la componen, la tratan y otros, por fin, le ponen un título, le agregan una leyenda y la comentan. El medio receptor es el público que lee el diario. Y el canal de transmisión, el diario mismo, o más precisamente, un complejo de mensajes concurrentes, cuyo centro es la fotografía y cuyos contornos están representados por el título, la leyenda, la compaginación, y de manera más abstracta, pero no menos, el nombre mismo del diario (pues ese nombre constituye un saber que puede desviar notablemente la lectura del mensaje propiamente dicho: Una foto puede cambiar de sentido al pasar de L'Aurore a L'Humanité). Estas constataciones no son indiferentes, pues vemos claramente que las tres partes tradicionales del mensaje no exigen el mismo método de exploración. Tanto la emisión como la recepción del mensaje dependen de una sociología: se trata de estudiar grupos humanos, de definir móviles, actitudes y de intentar relacionar el comportamiento de esos grupos con la sociedad total de la que forman parte. Pero para el mensaje en sí, el método debe ser diferente: cualquiera sea el origen y el destino del mensaje, la fotografía no es tan sólo un producto o una vía, sino también un objeto dotado de una autonomía estructural. Sin pretender en lo más mínimo separar este objeto de su uso, es necesario prever en este caso un método particular, anterior al análisis sociológico mismo, y que no puede ser sino el análisis inmanente de esa estructura original que es una fotografía.

Es evidente que incluso desde el punto de vista de un análisis puramente inmanente, la estructura de la fotografia no es una estructura aislada; se comunica por lo menos con otra estructura, que es el texto que acompaña toda fotografía periodística. Por consiguiente, la totalidad de la información está sostenida por dos estructuras diferentes (una de las cuales es lingǘstica); estas dos estructuras son concurrentes, pero como sus unidades son heterogéneas, no pueden mezclarse; en un caso (el texto) la sustancia 
del mensaje está constituida por palabras; en el otro (la fotografía), por líneas, planos, tintes. Además, las dos estructuras del mensaje ocupan espacios reservados, contiguos, pero no, como por ejemplo en un jeroglífico que funde en una sola línea la lectura de las palabras y las imágenes. De este modo, y aunque no haya nunca fotografías periodísticas sin comentario escrito, el análisis debe apuntar en primer término a cada estructura por separado; y sólo cuando se haya agotado el estudio de cada estructura podrá entenderse la forma en que se complementan. De estas dos estructuras, una, la de la lengua, ya es conocida (lo que no se conoce es la de la que constituye el habla del diario; en este sentido queda aún un enorme trabajo por realizar); la otra, la de la fotografía propiamente dicha, es prácticamente desconocida. Nos limitaremos aquí a definir las primeras dificultades de un análisis estructural propiamente dicho.

\section{La paradoja fotográfica}

¿Cuál es el contenido del mensaje fotográfico? ¿Qué transmite la fotografía? Por definición, la esencia en sí, lo real literal. Del objeto a su imagen hay por cierto una reducción: de proporción, de perspectiva y de color. Pero esta reducción no es en ningún momento una transformación (en el sentido matemático del término). Para pasar de lo real a su fotografía, no es necesario segmentar esa realidad en unidades y erigir esas unidades en signos sustancialmente diferentes del objeto cuya lectura proponen. Entre ese objeto y su imagen, no es necesario disponer de un relevo (relais), es decir, de un código. Si bien es cierto que la imagen no es lo real, es por lo menos su analogon perfecto, y es precisamente esa perfección analógica lo que, para el sentido común, define la fotografía. Aparece así la característica particular de la imagen fotográfica: es un mensaje sin código, proposición de la cual es preciso deducir de inmediato un corolario importante: el mensaje fotográfico es un mensaje continuo.

¿Existen otros mensajes sin código? A primera vista sí: precisamente todas las reproducciones analógicas de la realidad: dibujos, pinturas, cine, teatro. Pero en realidad, cada uno de estos mensajes desarrolla de manera inmediata y evidente, además del contenido analógico en sí (escena, objeto, paisaje), un mensaje suplementario, que es lo que llamaremos corrientemente estilo de la reproducción. Se trata en este caso de un sentido secundario, cuyo significante es un cierto de la imagen por parte del creador, y cuyo significado, ya sea estético o ideológico, remite a una cierta de la sociedad que recibe el mensaje. En suma, todas las estas imitativas contienen dos mensajes: un mensaje denotado que es el analogon en sí, y el mensaje connotado, que es la manera como la sociedad hace leer, en cierta medida, lo que piensa. Esta dualidad de los mensajes es evidente en todas las reproducciones no fotográficas: no hay dibujo, por que sea, cuya exactitud misma no se convierta en estilo; no hay escena filmada cuya objetividad no sea finalmente leída como el signo mismo de la objetividad. Tampoco en este caso se llevó a cabo el estudio de estos mensajes connotados (en primer lugar habría que decidir si lo que se llama obra de arte puede reducirse a un sistema de significaciones). Sólo puede preverse que en el caso de que todas estas artes imitativas sean comunes, es verosímil que el código del sistema connotado esté constituido ya sea 
por una simbólica universal, ya sea por una retórica de época, en una palabra, por una reserva de estereotipos (esquemas, colores, grafismos, gestos, expresiones, agrupaciones de elementos). Ahora bien, en principio nada de todo esto se da en la fotografía, en todo caso en la fotografía periodística que no es nunca fotografía. Al hacerse pasar por una analogía mecánica de lo real, en cierta medida, su mensaje primario llena por completo su sustancia y no deja lugar para el desarrollo de un mensaje secundario. En suma, de todas las estructuras de información, la fotografía sería la única que está exclusivamente constituida y ocupada por un mensaje, que agotaría por completo su ser. Ante una fotografía, el sentimiento de, o si se prefiere, de plenitud analógica, es tan fuerte, que su descripción es literalmente imposible, puesto que describir es precisamente adjuntar al mensaje denotado, un relevo o un mensaje secundario, tomado de un código que es la lengua, y que constituye fatalmente, por más cuidados que se tomen para ser exactos, una connotación respecto de lo análogo fotográfico: por consiguiente, describir no es tan sólo ser inexacto o incompleto, sino cambiar de estructura, significar algo distinto de lo que se muestra.

Ahora bien, este carácter puramente de la fotografia, la perfección y la plenitud de su analogía, en una palabra (es decir las características que el sentido común asigna a la fotografia) corren el riesgo de ser míticos, pues de hecho, hay una gran probabilidad (y esto será una hipótesis de trabajo) de que el mensaje fotográfico (al menos el mensaje periodístico) sea connotado. La connotación no se deja necesariamente captar de inmediato a nivel de mensaje en sí (es, si se quiere, a la vez invisible y activa, clara e implícita), pero se la puede inducir de ciertos fenómenos que tienen lugar a nivel de la producción y de la recepción del mensaje: por una parte, una fotografía periodística es un objeto de trabajo, seleccionado, compuesto, construido, tratado según normas profesionales, estéticas o ideológicas, que son otros tantos factores de connotación; y por otra, esta misma fotografía no es solamente percibida, recibida, sino también leída, relacionada más o menos conscientemente por el público que la consume, con una reserva tradicional de signos. Ahora bien, todo signo supone un código, y es precisamente este código (de connotación) lo que habría que tratar de establecer. La paradoja fotográfica sería entonces la coexistencia de dos mensajes, uno sin código (lo análogo fotográfico) y el otro con código (el o el tratamiento, o la o la retórica fotográfica). Estructuralmente, la paradoja no es la colusión de un mensaje denotado y de mensaje connotado: esa es la característica probablemente fatal de todas las comunicaciones de masa. Lo que sucede es que el mensaje connotado (o codificado) se desarrolla en este caso a partir de un mensaje sin código. Esta paradoja estructural coincide con una paradoja ética cuando queremos ser, nos esforzamos por copiar minuciosamente lo real como si lo analógico fuera un factor que se resiste a la incorporación de valores (esta es, al menos, la definición del estético). ¿Cómo la fotografía puede ser al mismo tiempo y contener valores, natural y cultural? Esta pregunta podrá tal vez ser contestada sólo cuando haya sido posible captar el modo de imbricación del mensaje denotado y del mensaje connotado. Pero para emprender este trabajo hay que recordar que, en la fotografía, el mensaje denotado es absolutamente analógico, es decir, que no recurre a código alguno, es continuo; por consiguiente, no hay motivos para buscar las unidades 
significantes del primer mensaje. Por el contrario, el mensaje connotado contiene un plano de expresión y un plano de contenido, significantes y significados: obliga pues a un verdadero desciframiento. Este desciframiento sería actualmente prematuro, pues para aislar las unidades significantes y los temas (o valores) significados, habría que realizar lecturas dirigidas (quizás por medio de tests), haciendo variar artificialmente ciertos elementos de la fotografia para observar si esas variaciones de forma provocan variaciones de sentido. $\mathrm{Al}$ menos prever desde ahora los principales planos de análisis de la connotación fotográfica.

\section{Los procedimientos de connotación}

La connotación, es decir la imposición de un sentido secundario al mensaje fotográfico propiamente dicho, se elabora en los diferentes niveles de producción de la fotografía (selección, tratamiento técnico, encuadre, compaginación): es, en suma, una codificación deloanalógicofotográfico.Esposible,porconsiguiente,irdesentrañandoprocedimientos de connotación; pero no hay que olvidar que estos procedimientos no tienen nada que ver con unidades de significación, tales como un ulterior análisis semántico permitirá quizás definirlas: estrictamente hablando, no forman parte de la estructura fotográfica. Estos procedimientos son conocidos; nos limitaremos a traducirlos en términos estructurales. En rigor, habría que separar los tres primeros (trucaje, pose, objetos) de los tres últimos (fotogenia, asteticismo, sintaxis), puesto que en esos tres primeros procedimientos, lo que produce la connotaciones una modificación de lo real, es decir, del mensaje denotado (es evidente que este preparativo no es propio de la fotografia). Sin embargo, si se los incluye en los procedimientos de connotación fotográfica, es porque ellos también se benefician con el prestigio de la denotación: La fotografia permite que el fotógrafo esquive la preparación que impone a la escena que va a captar. Pero no por eso, desde el punto de vista de un ulterior análisis estructural, puede asegurarse que sea posible tener en cuenta el material que entregan.

1. Trucaje. En 1951, una fotografia ampliamente difundida en los periódicos norteamericanos, costaba su banca, según parece, al senador Millard Tydings; esta fotografía representaba al senador conversando con el líder comunista Earl Browder. Se trataba, en realidad, de una foto trucada, constituida por el acercamiento artificial de los dos rostros. El interés metódico del trucaje consiste en que interviene, sin dar aviso, dentro del mismo plano de denotación; utiliza la credibilidad particular de la fotografia, que no es, como vimos, más que su excepcional poder de denotación, para hacer pasar por simplemente denotado un mensaje que no es, en realidad, fuertemente connotado; no hay ningún otro tratamiento en el que la connotación adopte en forma tan completa la máscara de la denotación. Es evidente que la significación sólo es posible en la medida que existe una reserva de signos, un esbozo de código; en este caso, el significante es la actitud (la conversación) de los dos personajes; señalaremos que esta actitud no se convierte en signo más que para una cierta sociedad, es decir sólo frente a determinados valores: lo que transforma el gesto de los interlocutores en signo de una familiaridad condenable es el anticomunismo puntilloso del electorado 
americano; en otras palabras, el código de connotación no es ni artificial (como una lengua verdadera), ni natural: es histórico.

2.Pose. Veamosunafotografiaperiodística ampliamente difundida en elmomento de las últimas elecciones norteamericanas: es el busto del presidente Kennedy visto de perfil, los ojos hacia lo alto, las manos juntas. En este caso, lo que prepara la lectura de los significados de connotación es la pose misma del sujeto: juventud, espiritualidad, pureza. La fotografía no es por cierto significante más que porque existe una reserva de actitudes estereotipadas que constituyen elementos de significación ya preparados (mirada hacia lo alto, manos juntas); una de la connotación iconográfica debería pues buscar sus materiales en la pintura, el teatro, las asociaciones de ideas, las metáforas corrientes, etc., es decir, precisamente, enla. Como se dijo, la pose no es un procedimiento específicamente fotográfico, pero es difícil dejar de nombrarlo, en la medida en que su efecto proviene del principio analógico que fundamentará la fotografía: el mensaje no es aquí sino: el lector recibe como simple denotación lo que de hecho es una estructura doble, denotada/connotada.

3. Objetos. Tenemos que reconocer aquí una importancia particular a lo que podría llamarse la pose de los objetos, puesto que el sentido connotado surge entonces de los objetos fotografiados (ya sea que el fotógrafo haya tenido la oportunidad de disponer artificialmente esos objetos frente al objetivo, ya sea que entre varias fotografías el compaginador elija la de tal o cual objeto). Lo interesante es que esos objetos son inductores corrientes de asociaciones de ideas (biblioteca = intelectual), o, de manera más oscura, verdaderos símbolos (la puerta de la cámara de gas de Chessmann remite a la puerta fúnebre de las antiguas mitologías). Estos objetos constituyen excelentes elementos de significación: por una parte, son discontinuos y complejos en sí mismos, lo cual para un signo es una cualidad física; y por otra, remites a significados claros, conocidos. Por consiguiente, son los elementos de un verdadero léxico, estables al punto de poder constituirse fácilmente en sintaxis. Veamos por ejemplo una de objetos: una ventana abierta sobre techos de tejas, un paisaje de viñedos; ante la ventana, un álbum de fotografias, una lupa, un jarro con flores; estamos pues en el campo, al sud de la Loire (viñedos y tejas), en una casa burguesa (flores sobre la mesa), cuyo anciano morador (lupa) revive sus recuerdos (álbum de fotografias): se trata de Franáois Mauriac en Malagar (foto aparecida en Paris-Match).

En alguna medida, la connotación de todas esas unidades significantes, sin embargo, como si se tratase de una escena inmediata y espontánea, es decir insignificante; se encuentra explicitada en el texto, que desarrolla el tema de los vínculos que unen a Mauriac con la tierra. Es posible que el objeto ya no posea una fuerza, pero posee con toda seguridad un sentido.

4. Fotogenia. Ya se hizo la teoría de la fotogenia (Edgar Morin en Le Cinéma ou l'Homme imaginaire) y no es este el lugar para insistir acerca de la significación 
general de este procedimiento. Bastará definir la fotografía en términos de estructura informativa: en la fotogenia, el mensaje connotado está en la imagen misma, (es decir en general sublimada), por técnicas de iluminación, de impresión y de revelado. Sería necesario hacer un recuento de estas técnicas, sólo en la medida en que a cada una de ellas corresponde un significado de connotación suficientemente constante como para poder ser incorporado a un léxico cultural de los técnicos (por ejemplo el lanzado por los equipos del doctor Steinert para significar el espacio-tiempo). Este recuento sería además una excelente ocasión para distinguir los efectos estéticos de los efectos significantes -salvo que se llegue a la conclusión de que en fotografía, contrariamente a las intenciones de los fotógrafos de exposición, no hay nunca arte sino siempre sentidolo que opondría precisamente, según un criterio preciso, la buena pintura, así fuese marcadamente figurativa, a la fotografía.

5. Esteticismo. Aparentemente, sólo puede hablarse de esteticismo en fotografía de manera ambigua: cuando la fotografía se hace pintura, es decir composición o sustancia visual deliberadamente tratada como, ya sea para significarse a sí misma como (es el caso del de comienzos de siglo), ya sea para imponer un significado por lo general más sutil y más complejo de lo que lo permiten otros procedimientos de connotación. Así por ejemplo, Cartier-Bresson representó el recibimiento que los fieles de Lisieux tributaron al Cardenal Pacelli como un cuadro antiguo; pero esta fotografía no es en absoluto un cuadro. Por una parte, su esteticismo manifiesto remite (maliciosamente) a la idea misma de cuadro (lo cual es contrario a toda pintura verdadera), y por otra, la composición significa aquí, abiertamente, una cierta espiritualidad estática, traducida en términos de espectáculo objetivo. En este caso vemos además la diferencia entre la fotografía y la pintura: en el cuadro de un Primitivo, la no es nunca un significado, sino, por así decirlo, el ser mismo de la imagen; es cierto que en algunas pinturas puede haber elementos de código, figuras de retórica, símbolos de época; pero no unidades significantes que remitan a la espiritualidad, que es una manera de ser, no el objeto de un mensaje estructurado.

6. Sintaxis. Ya hablamos de una lectura discursiva de objetos-signos dentro una misma fotografia; es natural que varias fotografias puedan transformarse en secuencia (es el caso corriente de las revistas ilustradas); el significante de connotación ya no se encuentra entonces a nivel de ninguno de los fragmentos de la secuencia, sino a nivel (suprasegmental como dirían los lingüistas) del encadenamiento. Veamos cuatro instantáneas de una cacería presidencial en Rambouillet; en cada una de ellas el ilustre cazador (Vincent Auriol) apunta su fusil en una dirección imprevista, con gran peligro para los guardias que huyen o se tiran al suelo: la secuencia (y sólo ella) ofrece como lectura una situación cómica, que surge, según un procedimiento bien conocido, de la repetición y de la variación de las actitudes. En este sentido señalaremos que la fotografía solitaria es rara vez (es decir difícilmente) cómica, al contrario del dibujo; lo cómico necesita movimiento, es decir repetición (lo que es fácil en el cine), o tipificación (lo que es posible en el dibujo), y estas dos le están vedadas a la fotografia. 


\section{El texto y la imagen}

Tales son los principales procedimientos de connotación de la imagen fotográfica (repitamos una vez más que se trata de técnicas, no de unidades). Podemos agregar de modo constante el texto mismo que acompaña la fotografía periodística. Se imponen aquí tres observaciones.

En primer lugar la siguiente: el texto constituye un mensaje parásito, destinado a connotar la imagen, es decir, a uno o varios significados secundarios. En otras palabras, y eso representa un vuelco histórico importante, la imagen ya no ilustra la palabra; es la palabra que, estructuralmente, es parásita de la imagen. Este vuelco tiene su precio: en las formas tradicionales de la imagen funcionaba como una vuelta episódica a la denotación, a partir de un mensaje principal (el texto) sentido como connotado, puesto que necesitaba, precisamente, una ilustración; en la relación actual, la imagen no viene a aclarar o a la palabra; es la palabra que viene a sublimar, patentizar o racionalizar la imagen; pero como esta operación se hace a título accesorio, el nuevo conjunto informativo parece fundarse principalmente en un mensaje objetivo (denotado), del cual la palabra no es más que una suerte de vibración secundaria, casi inconsecuente. Antes, la imagen ilustraba el texto (lo hacía más claro); hoy en día el texto hace más pesada la imagen, le impone una cultura, una moral, una imaginación; antes había una reducción del texto a la imagen, hoy, una amplificación de una a otra: la connotación ya no se vive más que como la resonancia natural de la denotación fundamental constituida por la analogía fotográfica. Nos encontramos pues frente a un proceso caracterizado de naturalización de lo cultural.

Otra observación: el efecto de connotación es probablemente diferente según el modo de presentación de la palabra; cuanto, más cerca se encuentra de la imagen, menos parece connotarla; atrapado en alguna medida por el mensaje iconográfico, el mensaje verbal parece participar de su objetividad, la connotación del lenguaje se vuelve a través de la denotación de la fotografía. Es cierto que no hay nunca una verdadera incorporación, puesto que las sustancias de ambas estructuras (en un caso gráfica, en el otro icónica) son irreductibles; pero es probable que en esa amalgama existan grados, es posible que la leyenda tenga un efecto de connotación menos evidente que la de los títulos o los artículos; título y artículo se separan sensiblemente de la imagen, el título por su impresión, el artículoporsu distancia, unoporque rompe, elotroporquealeja elcontenidodelaimagen; la leyenda, por el contrario, por su misma disposición, por su medida promedio de lectura, parece reforzar la imagen, es decir, participar en su denotación.

Sin embargo, es imposible (y esta será la última observación respecto del texto) que la palabra la imagen, pues en el pasaje de una estructura a otra, se elaboran fatalmente significados secundarios. ¿Cuál es la relación que estos significados de connotación mantienen con la imagen? Aparentemente se trata de una explicación, es decir, en cierta medida, de un énfasis; en efecto, la mayoría de las veces el texto no hace más que amplificar un conjunto de connotaciones que ya están incluidas en la fotografia; 
pero también a veces el texto produce (inventa) un significado enteramente nuevo y que, de alguna manera, se proyecta retroactivamente en la imagen, hasta el punto de parecer denotado: , dice el título de una fotografía en la que se ve a la reina Isabel y a Felipe de Edimburgo bajando de un avión; sin embargo, en el momento de la fotografía, estos dos personajes ignoraban por completo el accidente aéreo del que acaban de escapar. A veces, la palabra puede también llegar a contradecir la imagen de modo de producir una connotación compensatoria. Un análisis de Gerbner (The social anatomy of the romance confession cover-girl) mostró que en ciertas revistas sentimentales, el mensaje verbal de los títulos de la tapa (de contenido sombrío y angustioso) acompañaba siempre la imagen de una cover-girl radiante; los dos mensajes entran aquí en un compromiso; la connotación tiene una función reguladora, preserva el juego irracional de la proyección-identificación.

\section{La insignificancia fotográfica}

Ya hemos dicho que el código de la connotación no es, verosímilmente, ni "natural" ni "artificial”, sino histórico, o si se prefiere "cultural". En él los signos son gestos, actitudes, expresiones, colores o efectos, provistos de ciertos sentidos en virtud del uso de una cierta sociedad: la relación entre el significante y el significado, es decir la significación, es, si no inmotivada, al menos enteramente histórica. Por consiguiente, no puede decirse que el hombre moderno proyecte en la lectura de la fotografia sentimientos y valores caracterológicos o, es decir infra o trans-históricos, más que si se precisa con toda claridad que la significación es siempre elaborada por una sociedad y una historia definidas; la significación es, en suma, el movimiento dialéctico que resuelve la contradicción entre el hombre cultural y el hombre natural.

Por consiguiente, gracias a su código de connotación, la lectura de la fotografía es siempre histórica; depende del lector, como si se tratara de una lengua verdadera, inteligible sólo si se conocen sus signos. En resumidas cuentas, el fotográfico no dejaría de recordar ciertas lenguas ideográficas, en las cuales unidades analógicas y unidades descriptivas están mezcladas, con la diferencia de que el ideograma es vivido como un signo, en tanto que la fotográfica pasa por ser denotación pura y simple de la realidad. Encontrar este código de connotación sería, entonces, aislar, enumerar y estructurar todas las partes de la superficie fotográfica cuya discontinuidad misma depende de un cierto saber del lector, o, si se prefiere, de su situación cultural.

Ahora bien, en esta tarea quizá sea necesario llegar bastante lejos. Nada indica que en la fotografía haya partes o que la insignificancia completa de la fotografía sea quizá totalmente excepcional. Para resolver este primer problema, habría que dilucidar en primer término los mecanismos de lectura (en el sentido físico y semántico de término), o, si se prefiere, de percepción de la fotografía. Ahora bien, en este sentido no sabemos gran cosa: ¿cómo leemos una fotografía? ¿Qué percibimos? ¿En qué orden, según qué itinerario? ¿Qué es incluso percibir? Sí, según ciertas hipótesis de Bruner y Piaget, no hay percepción sin categorización inmediata, la fotografía se verbaliza en el momento 
mismo en que se percibe; o, mejor dicho, no se percibe más que verbalizada (si la verbalización tarda, se produce un desorden de la percepción, interrogación, angustia delsujeto, traumatismo, según la hipótesis de G. Cohen-Séat a propósito de la percepción filmica). Desde este punto de vista, la imagen captada de inmediato por un metalenguaje interior -la lengua-, no conocería en suma ningún estado denotado. Socialmente, sólo existiría sumergida por lo menos en una primera connotación, precisamente la de las categorías de la lengua; y se sabe que toda lengua toma partido a favor de las cosas, que connota lo real, aunque más no fuera segmentándolo; por consiguiente, las connotaciones de la fotografias coincidirían, en términos generales, con los grandes planos de connotación del lenguaje.

De esta suerte, además de la connotación, hipotética pero posible, se encontrarían modos de connotación más particulares. En primer término, una connotación, cuyos significantes estarían seleccionados, localizados, en ciertas partes del analogon: ante tal vista de ciudad, sé que estoy en un país del norte de África, porque veo a la izquierda un cartel escrito en caracteres arábigos, en el centro un hombre vestido con una gandurah, etc.; en este caso la lectura depende estrechamente de mi cultura, de mi conocimiento del mundo; y es probable que una buena foto periodística (y todas lo son, puesto que están seleccionadas) juegue con el saber supuesto de sus lectores, eligiendo los clichés que contienen la mayor cantidad posible de informaciones de este tipo, de manera de euforizar la lectura. Si se fotografía Agadir destruida, más vale disponer de algunos signos, aunque la no tenga nada que ver con el desastre en sí, pues la connotación proveniente del saber es siempre una fuerza tranquilizadora: al hombre le gustan los signos, y le gustan claros.

Connotación perceptiva, connotación cognitiva: queda aún el problema de la connotación ideológica (en el sentido amplio del término) o ética, que introduce en la lectura de la imagen razones o valores. Se trata de una connotación fuerte, exige un significante muy elaborado, casi diríamos sintáctico: encuentro de personajes (lo vimos a propósito del trucaje), desarrollo de actitudes, constelación de objetos. El hijo del Shah de Persia acaba de nacer: en la fotografía vemos: la realeza (cuna dorada por una multitud de servidores que la rodean), la riqueza (varias nurses), la higiene (guardapolvos blancos, techo de la cuna de plexi-glass), la condición, pese a todo humana, de los reyes (el bebé llora), es decir todos los elementos contradictorios del mito principesco, tal como lo consumimos en la actualidad. En este caso se trata de valores apolíticos, y el léxico es rico y claro. Es posible (pero esto no es más que una hipótesis) que por el contrario, la connotación política esté la mayoría de las veces confiada al texto, en la medida en que las selecciones políticas son siempre, por así decirlo, de mala fe: de determinada fotografía puedo dar una lectura de derecha o una lectura de izquierda (ver en este sentido una encuesta del I.F.O.P. publicada por Les Temps modernes, (1955). La denotación, o su apariencia, es una fuerza que no logra modificar las opciones políticas: nunca ninguna fotografía convenció o desmintió a nadie (pero puede), en la medida en que la conciencia política es tal vez inexistente fuera los logos: la política es lo que permite todos los lenguajes. 
Estas observaciones bosquejan una suerte de cuadro diferencial de las connotaciones fotográficas; en todo caso, puede verse que la connotación llega muy lejos. ¿ ¿ignifica esto que sea imposible una pura denotación, un más acá del lenguaje? Si existe, no es tal vez a nivel de lo que el lenguaje corriente llama lo insignificante, lo neutro, lo objetivo, sino más bien a nivel de las imágenes propiamente traumáticas: el trauma es precisamente lo que suspende el lenguaje y bloquea la significación. Es cierto que en un proceso de significación fotográfica pueden captarse situaciones normalmente traumáticas; lo que sucede es que precisamente ene se momento son señaladas a través de un código retórico que la distancia, las sublima, las aplaca. Son raras las fotografía propiamente traumáticas, pues en fotografía el trauma es enteramente tributario de la certeza de que la escena tuvo realmente lugar: era necesario que el fotógrafo estuviese allí (definición mítica de la denotación); pero una vez sentado esto (que a decir verdad ya es una connotación), la fotografía traumática (incendios, naufragios, catástrofes, muertes violentas captadas es aquella de la cual no hay nada que decir: la foto-choque es por estructura insignificante: ningún valor, ningún saber, en última instancia ninguna categorización verbal pueden influir en el procesoinstitucional de la significación. Podría entonces imaginarse una suerte de ley: cuanto más directo es el trauma, tanto más difícil la connotación; o bien, el efecto de una fotografía es inversamente proporcional a su efecto traumático.

¿Por qué? Lo que sin duda sucede es que, como toda significación bien estructurada, la connotación fotográfica es una actividad institucional. A nivel de la sociedad total, su función es integrar al hombre, es decir, tranquilizarlo. Todo código es a la vez arbitrario y racional y recurrir a un código es para el hombre un modo de comprobarse, de probarse a través de una razón y una libertad. En este sentido, es posible que el análisis de los códigos permita definir históricamente una sociedad con mayor seguridad y facilidad que el análisis de sus significados, pues éstos pueden aparecer a menudo como transhistóricos, pertenecientes a un fondo antropológico más que a una historia verdadera: Hegel definió mejor a los antiguos griegos cuando esbozó la manera como significaban la naturaleza, que cuando describió el conjunto de sus referidas a este tema. Del mismo modo quizás haya algo más útil que hacer directamente el recuento de los contenidos ideológicos de nuestro tiempo, pues al tratar de reconstituir en su estructura específica de connotación de una comunicación tan amplia como lo es la fotografía periodística, podemos esperar encontrar, en su fineza misma, las formas que nuestra sociedad utiliza para tranquilizarse, y captar así la medida, los rodeos y la función profunda de este esfuerzo. La perspectiva es tanto más atractiva, como dijimos al comienzo, cuanto que en lo relativo a la fotografía, se desarrolla bajo la forma de una paradoja: la que hace de un objeto inerte un lenguaje y transforma la incultura de una arte, en la más social de las instituciones. 